are known to me. I understand that another deep-sea expedition will be made by our enterprising neighbours next summer, being the fourth in consecutive years. ${ }^{1}$

December 21, I 883

J. GWYN JEFFREYS

\section{THE SUN MOTOR AND THE SUN'S TEMPERATURE}

THE annexed illustration (Fig. I) represents a perspective view of a sun motor constructed by the writer, and put in operation last summer. This mechanical device for utilising the sun's radiant heat is the result of experiments conducted during a series of twenty years; a succession of experimental machines of similar general design, but varying in detail, having been built during that period. The leading feature of the sun motor is that of concentrating the radiant heat by means of a rectangular trough having a curved bottom lined on the inside with polished plates so arranged that they reflect the sun's rays towards a cylindrical heater placed longitudinally above the trough. This heater, it is scarcely necessary to state, contains the acting medium, steam or air, employed to transfer the solar energy to the motor; the transfer being effected by

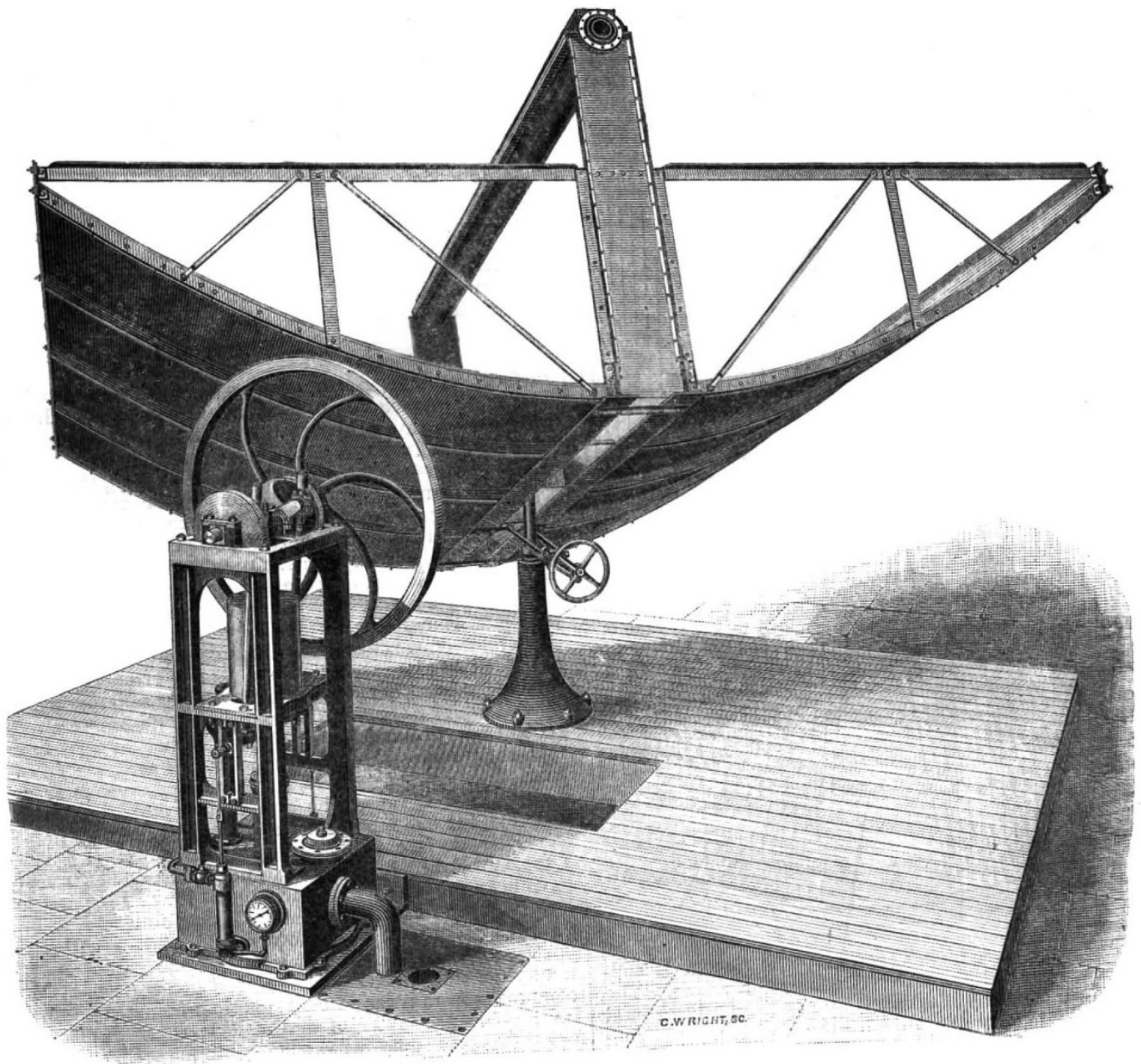

Ericsson's Sun Motor, erected at New York, 1883.

means of cylinders provided with pistons and valves resembling those of motive engines of the ordinary type. Practical engineers as well as scientists have demonstrated that solar energy cannot be rendered available for producing motive power, in consequence of the feebleness of solar radiation. The great cost of large reflectors and the difficulty of producing accurate curvature on a large scale, besides the great amount of labour called for in

${ }^{x}$ P.S. - In NATURE of December 20 (p. $\left.{ }^{1} 7_{2}\right)$, I cverlooked the misprint of India fur Sweden. - J. G. J. freventing the polished surface from becoming tarnished, are objections which have been supposed to render direct solar energy practically useless for producing mechanical power.

The device under consideration overcomes the stated objections by very simple means, as will be seen by the following description:--The bottom of the rectangular trough consists of straight wooden staves, supported by iron ribs of parabolic curvature secured to the sides of the trough. On these staves the reflecting plates, consisting 
of flat window glass silvered on the under side, are fastened. It will be readily understood that the method thus adopted for concentrating the radiant heat does not call for a structure of great accuracy, provided the wooden staves are secured to the iron ribs in such a position that the silvered plates attached to the same reflect the solar rays towards the heater. Fig. 2 represents a transverse section of the latter, part of the bottom of the trough, and sections of the reflecting plates; the direct and reflected solar rays being indicated by vertical and diagonal lines.

Referring to the illustration, it will be seen that the trough, II feet long, and 16 feet broad, including a parallel opening in the bottom, I 2 inches wide, is sustained by a light truss attached to each end ; the heater being supported by vertical plates secured to the truss. The heater is $6 \frac{1}{4}$ inches in diameter, 1 I feet long, exposing $130 \times 9.8=1274$ superficial inches to the action of the reflected solar rays. The reflecting plates, each 3 inches wide and 26 inches long, intercept a sunbeam of $130 X$

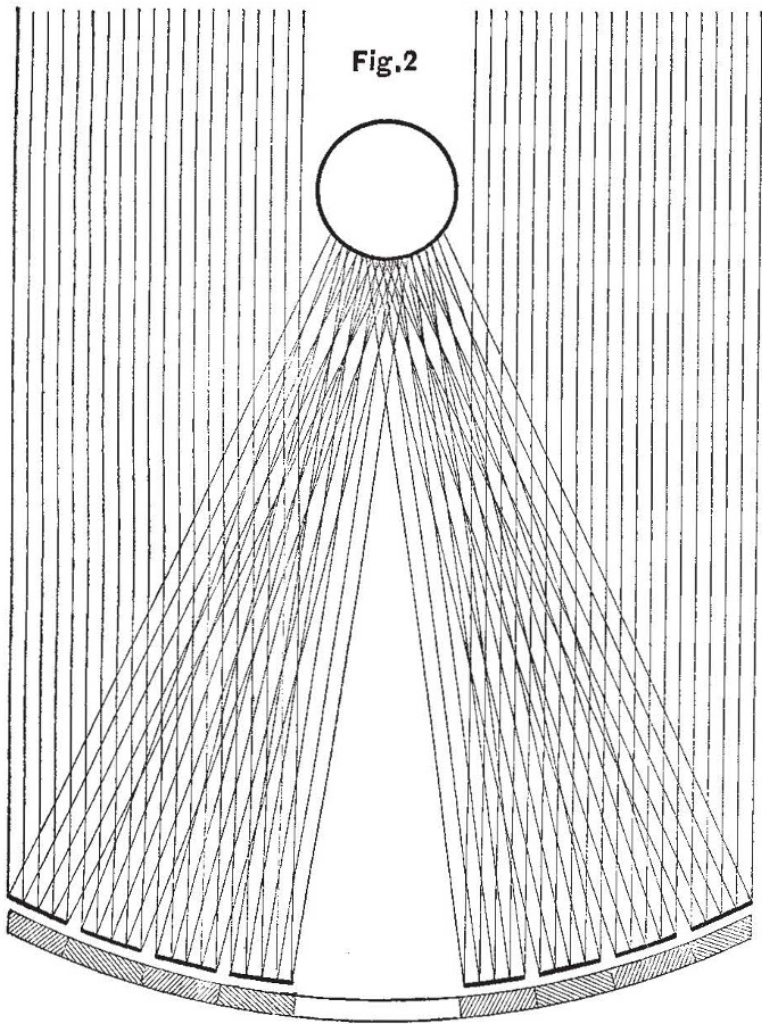

I $80=23,400$ square inches section. The trough is supported by a central pivot, round which it revolves. The change of inclination is effected by means of a horizontal axle-concealed by the trough-the entire mass being so accurately balanced that a pull of five pounds applied at the extremity enables a person to change the inclination or cause the whole to revolve. A single revolution of the motive engine develops more power than needed to turn the trough, and regulate its inclination so as to face the sun, during a day's operation.

The motor shown by the illustration is a steam-engine, the working cylinder being 6 inches in diameter, with 8 inches stroke. The piston rod, passing through the bottom of the cylinder, operates a force-pump of 5 inches diameter. By means of an ordinary cross-head secured to the piston-rod below the steam cylinder, and by ordinary connecting rods, motion is imparted to a crank shaft and fly-wheel, applied at the top of the engine frame; the object of this arrangement being that of showing the capability of the engine to work either pumps or mills. It should be noticed that the flexible steampipe employed to convey the steam to the engine, as well as the steam chamber attached to the upper end of the heater, have been excluded in the illustration. The average speed of the engine during the trials last summer was 120 turns per minute, the absolute pressure on the working piston being 35 lbs. per square inch. The steam was worked expansively in the ratio of $I$ to 3 , with a nearly perfect vacuum kept up in the condenser inclosed in the pedestal which supports the engine frame.

In view of the foregoing, experts need not be told that the sun motor can be carried out on a sufficient scale to benefit very materially the sun-burnt regions of our planet.

With reference to solar temperature, the power developed by the sun motor establishes relations between diffusion and energy of solar radiation which show that Newton's estimate of solar temperature must be accepted. The following demonstration, based on the foregoing particulars, will be readily comprehended.

The area of a sphere whose radius is equal to the earth's mean distance from the sun being to the area of the latter as $2 \mathrm{I} 4^{\cdot} 5^{3}: \mathrm{I}$, while the reflector of the solar motor intercepts a sunbeam of 23,400 square inches section, it follows that the reflector will receive the heat developed by $\frac{23400}{2145^{2}}=0.508$ square inch of the solar surface. Hence, as the heater of the motor contains I274 square inches, we establish the fact that the reflected solar rays acting on the same are diffused in the ratio of $1274: 0.508=2507: I$. Practice has now shown that, notwithstanding this extreme diffusion, the radiant energy transmitted to the reflector by the sun is capable of imparting a temperature to the heater of $520^{\circ} \mathrm{Fahr}$. above that of the atmosphere. The practical demonstration thus furnished by the sun motor enables us to determine with sufficient exactness the minimum temperature of the solar surface. It also enables us to prove that the calculations made by certain French scientists indicating that solar temperature does not exceed the temperatures produced in the laboratory are wholly erroneous. Had Pouillet known that solar radiation, after suffering a twothousand-five-hundred-and-seven-fold diffusion, retains a radiant energy of $520^{\circ} \mathrm{Fahr}$, he would not bave asserted that the temperature of the solar surface is $1760^{\circ} \mathrm{C}$. Accepting Newton's law that "the temperature is as the density of the rays," the temperature imparted to the heater of the sun motor proves that the temperature of the solar surface cannot be less than $520^{\circ} \times 2507=$ $1,303,640^{\circ} \mathrm{Fahr}$. Let us bear in mind that, while attempts have been made to establish a much lower temperature than Newton's estimate, no demonstration whatever has yet been produced tending to prove that the said Iaw is unsound. On the contrary, the most careful investigations show that the temperature produced by radiant heat emanating from incandescent spherical bodies diminishes inversely as the diffusion of the heat rays. Again, the writer has proved by his vacuum-actinometer, inclosed in a vessel maintained at a constant temperature during the observations, that for equal zenith distance the intensity of solar radiation at midsummer is $5^{\circ} .88 \mathrm{Fahr}$. less than during the winter solstice. This diminution of the sun's radiant heat in aphelion, it will be found, corresponds within $0^{\circ} 40$ of the temperature which Newton's law demands. It is proposed to discuss this branch of the subject more fully on a future occasion.

The operation of the sun motor, it will be well to add, furnishes another proof in support of Newton's assumption that the energy increases as the density of the rass. The foregoing explanation concerning the reflection of the rays (see Fig. 2), shows that no augmentation of temperature takes place during their transmission from 
the reflector to the heater. Yet we find that an increase of the number of reflecting plates increases proportionably the power of the motor. Considering that the parallelism of the rays absolutely prevents augmentation of temperature during the transmission, it will be asked: What causes the observed increase of mechanical power? $\mathrm{Ob}$. viously, the energy produced by the increased density of the rays acting on the heater. The truth of the Newtonian doctrine, that the energy increases as the density of the ra)s, has thus been verified by a practical te, $t$ which cannot be questioned. It is scarcely necessary to observe that our computation of tempera:ure - I, $303,640^{\circ} \mathrm{Fahr}$ does not show maximum solir intensity, the following points, besides atmospheric absorption, not having been considered :- ( 1 ) The diminution of energy attending the passage of the heat rays througin the substance of the reflecting plates; (2) the diminution consequent on the great amount of heat $r$ idiated by the blackened surface of the heater; (3) the diminution of tenperature in the he iter caused by convection.

J. ERICSSON

\section{A CHRISTMAS VISIT TO BEN NEVIS OBSERVATORY}

A LTHOUGH I have no tale of perilous adventure or A hair-breadth escape to tell the readers of NATURE, yet I think that they will be intere ted to hear of the progress that is being made in the first British attempt at the cultivation of high-level meteorology. This interest will be all the greater that the hearty encouragement and support that the Ben Nevis experiment has received from all parts of the United Kingdom has given it the character of a national undertaking.

As most of the readers of NATURE doubtless know, the observatory is at present in the experimental stage. A good road to the top with bridges and waterways has been made, and a part of the building erected sufficient to shelter the observers. It was judged wise to build as little as possible, until experience should have taught us the peculiar difficulties to be contended with in the somewhat novel circumstances presented by the summit of Ben Nevis in winter time. For, although several high level meteorological observatories, and indeed many other human habitations, already exist at much greater heights above the sea, yet there is probably no spot at present inhabited all the year round that presents climatic vicissitudes so remarkable. When winter is over, the directors will have a full report, with practical suggestions from the superintendent, Mr. Omond, to guide them in their further operations. Still it was thought well that some of the governing body should see with their own eyes the state of the observatory, and the work of the observers during the cold season. Accordingly two of them (Mr. John Murray and myself) made a visit of inspection on December 26 th, of which I propose to give a few particulars.

Accompanied by Mr. Maclean, the contractor for the road and observatory buildings, we started from Fort William about 9.30 on Wednesday morning. At first the sky was dark and gloomy, and it was thought that Ben Nevis was to give a specimen of his worst weather. It was not cold however; in fact it was oppressively warm during the first thousand feet of the ascent from the farm of Ichantie where the new road begins. This, coupled with the fact that the pony which one of the party rode up the first 2500 feet of the hill somewhat forced the pace, made it a little uncomfortable for the two pedestrians. The newly made road, loosened by the frost, and sodden by the rain and melting snow, was in places very heavy. $U_{p}$ as far as the little lake (Loch an Meall aut Suidhe), however, the roadway had suffered no substantial damage, except that the fall of a large stone had carried away a small piece of the margin; and all the bridges and waterways were found in excellent condition. This is very satisfactory, for the snow has already been down to Fort
William ; and recently a very rapid thaw has carried it so completely away, that on the 26th very little was met with under 3000 feet. The test has thus been tolerably severe and yet up to 2600 feet or so the road on the 26 th was in far better condition than it was on the day of the opening ceremony. About the altitude just mentioned, a part of the road had been badly ploughed up by a spate of water from the melting snow; higher up still, the damage seemed to be less, but it was not so easy to judge, as the roadway was there gradually lost in the overlying snow.

As the party rose in height, the temperature of the air and the ardour of the pony ali ie fell, and then the walkers were left to the full enjoyment of their climb. During the latter part of the first 3000 feet, the mist had been so thick that the pony and its rider could scarcely be discerned a few yards off; but several hundre 1 feet higher, after the road had been finally lost sight of in the snow, and all the party were on foot, we sutdenly emerged about noon from the gloom of the mist into the brightest of daylight. Overhead the sky was blue, a fresh light breeze was blowing, and the reflected sunlight was shining in silvery masses on the undulating surface of the frozen snow. We soon reached Buchan's Well, the position of which had been marke I by a wooden pole; but the well itself was completely hidden by a deep snow-drift, which filled the hollow in which it lies. From this spot to the top, the ascent was made almost straight over the snow. At times it was steep and slippery, but the surface was so hard that we rarely sank over the ankles. Two of us were rough s'ol, one having a few cricketer's spikes screwed to the soles of his boots, the other a pair of steigeisen (climbing irons), the use of which he had learned several years ago during some excursions in the Tyrolese Alps. Mr. Maclean, who had not taken these precautions, fell once or twice, but fortunately without being hurt in any way. When near the last slope we descried Mr. Omond hacking away most assiduously with an iceaxe to prepare a way fur us, a needless precaution as far as the rough-shod members of the party were concerned.

The view from the plateau on the summit was mignificent. All round there floated a billowy ozean of white mist, from which rose masses of the same, piled up in plices li'se mountain ranges, and through which rose here and there black mountain pe iks (prominent amon r these Schiehallion). A way towards Fort William was stretche la black curtain of mist in striking contr.st with the snowwhiteness of the upper layer. Down in Glen Nevis a similar mass was seen, rolled and twisted by the aircurrents into the most fantastic shapes. So grand was the spectacle that one of our party insisted that we had before us the model from which Dante had drawn his vision of the entrance to hell.

The summit reached, the directors naturally looked around for the building, whose site they had chosen some five months before, and upon whose construction they had expended so much anxious thought. There was, however, nothing to be seen but two small dark-looking stumps rising a little over the surrounding snow flat, and alongside of the se a little mound of snow. The stumps turnet out to be the chimney and ventilator on the roof of the observatory, and the mound was a portico built by the observers with blocks of frozen snow to protect a snow staircase which had been carried down the side of the house to the doorway. Af.er descending under the translucent canopy and stumbling for a little in the unfamiliar darkness of the passage, we entered the main room of the observatory, which for the present serves as sitting. room; kitchen, and office combined. Here we found the table laid for our lunch; and very soon we were comforting ourselves w th hot coffee, cabin biscuits, and excellent Danish butter from the stores of the establishment. The whole ascent had occupied a little over three hours and a half.

The little room in which we sat contained the American 